\title{
Prevalence and Severity of Depression, Anxiety, and Stress During Pandemic of COVID-19 Among College Students in Addis Ababa, Ethiopia, 2020 A Cross Sectional Survey
}

\author{
Addisu Tadesse Sahile ${ }^{1, ~}$, Mikiyas Ababu ${ }^{2}$, Sinetsehay Alemayehu ${ }^{3}$, Haymanot Abebe ${ }^{3}$, \\ Getabalew Endazenew ${ }^{4}$, Mussie Wubshet ${ }^{2}$, Hana Getachew ${ }^{3}$, Tirhas Tadesse ${ }^{4}$ \\ ${ }^{1}$ Department of Public Health, Unity University, Addis Ababa, Ethiopia \\ ${ }^{2}$ Department of Public Health, Universal Medical College, Addis Ababa, Ethiopia \\ ${ }^{3}$ Department of Nursing, Universal Medical College, Addis Ababa, Ethiopia \\ ${ }^{4}$ Department of Social and Population Health, Yekatit 12 Hospital Medical College, Addis Ababa, Ethiopia
}

Email address:

sahdis91@gmail.com (A. T. Sahile)

${ }^{*}$ Corresponding author

\section{To cite this article:}

Addisu Tadesse Sahile, Mikiyas Ababu, Sinetsehay Alemayehu, Haymanot Abebe, Getabalew Endazenew, Mussie Wubshet, Hana Getachew, Tirhas Tadesse. Prevalence and Severity of Depression, Anxiety, and Stress During Pandemic of COVID-19 Among College Students in Addis Ababa, Ethiopia, 2020 A Cross Sectional Survey. International Journal of Clinical and Experimental Medical Sciences. Vol. 6, No. 6, 2020, pp. 126-132. doi: 10.11648/j.ijcems.20200606.13

Received: September 24, 2020; Accepted: October 9, 2020; Published: November 23, 2020

\begin{abstract}
Background: Coronaviruses are enveloped, positive, single-stranded large ribonucleic acid (RNA) viruses that infect various animals including humans which were first investigated by Tyrell and Bynoe in 1966. In Ethiopia, more than 26 million students were affected by school closures due to coronavirus surge. Objectives: The survey was aimed at assessing the prevalence and severity of depression, anxiety, and stress during the pandemic of COVID-19 among college students in Addis Ababa, Ethiopia, 2020. Methods: An online cross-sectional survey was conducted among 153 college students in Addis Ababa, Ethiopia, from April 27-May 07, 2020. A short version of Depression, Anxiety, and Stress (DAS 21) scale were used, to measure both the magnitude as well as their severity. Findings: The overall prevalence of depression was 51\% (95\%CI: $42.8-$ $59.1 \%$ ), of which $49 \%, 18.1 \%, 20.9 \%, 7.2 \%$, and $4.6 \%$ of participants had normal, mild, moderate, severe and extremely severe depression consecutively. The overall prevalence of anxiety was 51.6\% (95\%CI: 43.4-59.8\%), where $11 \%, 20.9 \%, 6.5 \%$, and $13.1 \%$ of the participants had mild, moderate, severe, and extremely severe anxiety symptoms respectively. The magnitude of stress was $11.1 \%(95 \% \mathrm{CI}: 6.6-17.2 \%)$ of which only $7.8 \%$ and $2.6 \%$ had mild and moderate stress symptoms. The odds of developing anxiety among the students with a family income of 2001-4999 birr and greater than 10,000 birr had 69.7\% (AOR: 0.303; 95\%CI: 0.102-0.901) and 79.5\% (AOR: 0.205, 95\%CI: 0.064-0.653) higher odds as those with a monthly income of less than 2000 birr. Conclusion: A higher prevalence of depression and anxiety was observed from the current study, whilst the level of stress is still higher. A higher monthly income was associated with the development of anxiety during the pandemic of COVID-19. Concerned bodies were recommended to work over the identified problems, besides; large scale study mainly focused on determinants of depression, anxiety, and stress was also emphasized.
\end{abstract}

Keywords: Prevalence, Depression, Anxiety, Stress, COVID-19, College Students

\section{Introduction}

Coronaviruses are enveloped, positive, single-stranded large RNA viruses that infect various animals including humans which were first investigated by Tyrell and Bynoe in
1966. [1] During January 2020, novel coronavirus was confirmed by World Health Organization (WHO) to cause respiratory illness in a cluster of people in Wuhan city, Hubei province, china [2], whereas the case fatality rate of Covid19 was much lower than SARS of 2003. [3, 4]

The epidemic brought not only risk of death, but also 
insufferable psychological pressure on people around the world. [5, 6] There were reports of the psychological impacts of the epidemic on older adults, medical staff, children, patients, and the public in general. However, no study on homestay followed depression, anxiety, and stress among college students in Ethiopia was investigated to date. [7-9]

The first coronavirus case; a Japanese citizen; in Ethiopia was reported as of March 13, 2020. [10] According to the estimation by United Economic Commission for Africa, 2.9 percentage points off of Ethiopia's economic growth for the fiscal year of 2020, was shaved of Covid-19. [11]

In Ethiopia, more than 26 million students were affected by school closures due to the coronavirus surge [11], the continuous spread of the epidemic, the fabrication of inconsistent news, and delays in starting colleges, schools, and universities are predictable to influence the mental health of college students.

Therefore, the current study was aimed at assessing the prevalence and severities of depression, anxiety, and stress during the pandemic of COVID-19 among college students in Addis Ababa, Ethiopia.

\section{Methods}

An Ethical Letter sought from Ethics and research review committee of Universal Medical and Business College, then an online cross-sectional survey was undertaken April 27, to May 07, 2020, among students at Universal Medical and Business College; one of the private Colleges in Addis Ababa; the capital city of Ethiopia. The college has been providing a teachinglearning program in three departments namely; Public Health Officer, Nursing, and Clinical Pharmacy. A total of 1630 students totally, of which 1259 attended the regular program. The source population was students who attended the college in the academic year of 2020 and the study population for the study was students who enrolled in the regular program. The students with severe medical conditions were excluded from the study. Due to the lockdown condition in Ethiopia, the students were approached through WhatsApp, Telegram, Messenger, and email. A total of 680 students were identified to use either of the communication applications. An online data collection tool was designed and executed by Google forms (docs.google/forms). The Google link to the questionnaire was sent to the identified participants through email, WhatsApp, and Telegram in groups and individually.

For measuring the outcome variables in this case; depression, anxiety, and stress; a short version of Depression, Anxiety, and Stress (DAS 21) scale was used, with some clarification made by the investigator for those who got in to confusion to understanding the constructs within the questionnaire. Constructs making up the outcome could first be computed then multiplied by two to measure the magnitude and their severities. [12] Accordingly, the magnitude for all the three of the outcomes was measured as present and absent, whilst for the severity, the following ranges were applied. For depression, normal (0-9), mild (10-13), moderate (14-20), severe (21-27), and extremely severe (28 and above). For anxiety, normal (0-7), mild (8-9), moderate (10-14), severe (15-19), and extremely severe (20 and above). For the stress; normal (0-14), mild (15-18), moderate (19-25), severe (2633 ), and extremely severe (34 and more).

The collected data were entered into SPSS 25.0, after looked for completeness, cleaned, and recoded, descriptive statistics as a summary for the finding. Tables and diagrams were used for data presentation.

\section{Results}

\subsection{Socio-Demographic Characteristics}

A total of 153 filled questionnaires returned from the distributed online survey with a response rate of $22.5 \%$. Thirty-two percent, $34.6 \%$, and $5.9 \%$ of female participants had depression, anxiety, and stress respectively. Participants in the age group of 22-24 years old took the larger proportion $23.5 \%, 23.5$, and $7.8 \%$ of depression, anxiety, and stress consecutively. Depression and anxiety mostly observed among single participants at a rate of $47.8 \%$ and $48.4 \%$, whilst all in all in case of stress. More than on third (37.9\%) and $39.9 \%$ of participants who live with their parents sustained depression and anxiety respectively. (Table 1)

Table 1. Socio-Demographic Characteristics of College Students in Addis Ababa, Ethiopia, May, 2020 (n=153). $\leq$

\begin{tabular}{|c|c|c|c|c|}
\hline \multirow{2}{*}{ Characteristics } & \multirow{2}{*}{ Category } & Depression & Anxiety & Stress \\
\hline & & N (\%) & $\mathbf{N}(\%)$ & $\mathbf{N}(\%)$ \\
\hline \multirow{3}{*}{ Gender } & Female & $49(32)$ & $53(34.6)$ & $9(5.9)$ \\
\hline & Male & $29(19)$ & $26(16.9)$ & $8(5.2)$ \\
\hline & $\leq 21$ & 29 (19) & $30(19.6)$ & $3(1.96)$ \\
\hline \multirow[t]{3}{*}{ Age in years } & $22-24$ & $36(23.5)$ & $36(23.5)$ & $12(7.8)$ \\
\hline & $\geq 25$ & $13(8.5)$ & $13(8.5)$ & $2(1.3)$ \\
\hline & Single & $73(47.7)$ & $74(48.4)$ & $17(11.1)$ \\
\hline \multirow[t]{3}{*}{ Marital Status } & Married & $4(2.6)$ & $4(2.6)$ & 0 \\
\hline & Divorce/widowed & $1(0.7)$ & $1(0.7)$ & 0 \\
\hline & Health Officer & $25(16.3)$ & $30(19.6)$ & $5(3.27)$ \\
\hline \multirow[t]{4}{*}{ Department } & Nursing & $35(22.9)$ & $34(22.2)$ & $10(6.5)$ \\
\hline & Pharmacy & $18(11.8)$ & $15(9.8)$ & $2(1.3)$ \\
\hline & First Year & $1(0.7)$ & $3(1.96)$ & 0 \\
\hline & Second Year & $18(11.8)$ & $19(12.4)$ & $4(2.6)$ \\
\hline \multirow[t]{3}{*}{ Year of education } & Third Year & $25(16.3)$ & $28(18.3)$ & $5(3.27)$ \\
\hline & Fourth Year & $34(22.2)$ & $27(17.7)$ & $7(4.6)$ \\
\hline & Fifth year & 0 & $2(1.3)$ & $1(0.7)$ \\
\hline
\end{tabular}




\begin{tabular}{|c|c|c|c|c|}
\hline \multirow{2}{*}{ Characteristics } & \multirow{2}{*}{ Category } & Depression & Anxiety & Stress \\
\hline & & N (\%) & $\mathbf{N}(\%)$ & $\mathbf{N}(\%)$ \\
\hline \multirow{3}{*}{ Live with } & Alone & $6(3.9)$ & $4(2.6)$ & $1(0.7)$ \\
\hline & With Parents & $58(37.9)$ & $61(39.9)$ & $7(4.6)$ \\
\hline & With Relatives & $14(9.2)$ & $14(9.1)$ & $9(5.9)$ \\
\hline \multirow{4}{*}{$\begin{array}{l}\text { Monthly Family Income } \\
\text { In Birr }\end{array}$} & $\leq 2000$ & $13(8.5)$ & $10(6.5)$ & $4(2.6)$ \\
\hline & $2001-4999$ & $19(12.4)$ & $23(15.4)$ & $8(5.2)$ \\
\hline & 5000-9999 & $19(12.4)$ & $19(12.4)$ & $3(1.96)$ \\
\hline & $\geq 10000$ & $27(17.7)$ & $27(17.7)$ & $2(1.3)$ \\
\hline
\end{tabular}

\subsection{Depression, Anxiety and Stress-related Characteristics}

Less than half (41.8\%) of participants never found feeling of hard to wind down and whereas $405 \%$ of participants found it hard to wind down at the rate of sometimes each. Less than half $(43.8 \%), 56.9 \%, 69.3 \%$, and $48.4 \%$ of participants never aware of dryness of their mouth, they couldn't seem to experience any positive feeling at all, experienced breathing difficulty and found it difficult to work up the initiative to do things respectively.

Less than half $(40.5 \%)$ of the participants felt that they were using a lot of nervous energy, $39.9 \%$ of the participants were intolerant of anything that kept them from getting on with what they were doing, and $37.3 \%$ felt difficult to relax at a rate of sometimes each. (Table 2)

Table 2. Homestay Followed Depression, Anxiety and Stress during COVID-19 pandemics among College students in Addis Ababa, Ethiopia, May 2020. $(n=153)$.

\begin{tabular}{|c|c|c|c|c|}
\hline \multirow{2}{*}{ Characteristics } & Never & Sometimes & Often & Amost Always \\
\hline & $\mathbf{N}(\%)$ & $\mathbf{N}(\%)$ & $\mathbf{N}(\%)$ & $\mathbf{N}(\%)$ \\
\hline I found it hard to wind down & $62(40.5)$ & $64(41.8)$ & $19(12.4)$ & $8(5.2)$ \\
\hline I was aware of dryness of my mouth & $67(43.8)$ & $46(30.1)$ & $15(9.8)$ & $25(16.3)$ \\
\hline I couldn't seem to experience any positive feeling at all & $87(56.9)$ & $43(28.1)$ & $9(5.9)$ & $14(9.2)$ \\
\hline $\begin{array}{l}\text { I experienced breathing difficulty (e.g. excessively rapid breathing, breathlessness } \\
\text { in the absence of physical exertion) }\end{array}$ & $106(69.3)$ & 2415.7) & $18(11.8)$ & $5(3.3)$ \\
\hline I found it difficult to work up the initiative to do things 74 (48.4) & $74(48.4)$ & $42(27.5)$ & $21(13.7)$ & $16(10.5)$ \\
\hline I tended to over-react to situations & $54(35.3)$ & $43(28.1)$ & $47(30.7)$ & $9(5.9)$ \\
\hline I experienced trembling (e.g. in the hands) & $89(58.2)$ & $29(19.0)$ & $20(13.1)$ & $15(9.8)$ \\
\hline I felt that I was using a lot of nervous energy & $54(35.3)$ & $62(40.5)$ & $25(16.3)$ & $12(7.8)$ \\
\hline I was worried about situations in which I might panic and make a fool of myself & $66(43.1)$ & $53(34.6)$ & $25(16.3)$ & $9(5.9)$ \\
\hline I felt that I had nothing to look forward to & $73(47.7)$ & $42(27.5)$ & $25(16.3)$ & $13(8.5)$ \\
\hline I found myself getting agitated I found it & $67(43.8)$ & $53(34.6)$ & $26(17.0)$ & $7(4.6)$ \\
\hline Difficult to relax & $56(36.6)$ & $57(37.3)$ & $31(20.3)$ & $9(5.9)$ \\
\hline I felt down-hearted and blue & $74(48.4)$ & $52(34.0)$ & $21(13.7)$ & $6(3.9)$ \\
\hline I was intolerant of anything that kept me from getting on with what I was doing & $53(34.6)$ & $61(39.9)$ & $27(17.6)$ & $12(7.8)$ \\
\hline I felt I was close to panic & $79(51.6)$ & $43(28.1)$ & $18(11.8)$ & $13(8.5)$ \\
\hline I was unable to become enthusiastic about anything & $76(49.7)$ & $48(31.4)$ & $18(11.8)$ & $11(7.2)$ \\
\hline I felt I wasn't worth much as a person & $78(51.0)$ & $50(32.7)$ & $23(15.0)$ & $2(1.3)$ \\
\hline I felt that I was rather touchy & $68(44.4)$ & $45(29.4)$ & $33(21.6)$ & $7(4.6)$ \\
\hline $\begin{array}{l}\text { I was aware of the action of my heart in the absence of physical exertion (e.g. } \\
\text { sense of heart rate increase, heart missing a beat) }\end{array}$ & $79(51.6)$ & $31(20.3)$ & $33(21.6)$ & $10(6.5)$ \\
\hline I felt scared without any good reason & $75(49.0)$ & $45(29.4)$ & $27(17.6)$ & $6(3.9)$ \\
\hline I felt that life was meaningless & $98(64.1)$ & $27(17.6)$ & $17(111)$ & $11(7.2)$ \\
\hline
\end{tabular}

\subsection{Magnitude and Severity of Depression, Anxiety, and Stress}

Regarding the severity of depression, $49 \%, 18.1 \%, 20.9 \%$, $7.2 \%$, and $4.6 \%$ of participants had normal, mild, moderate, severe, and extremely severe depression consecutively.

Eleven percent, $20.9 \%, 6.5 \%$, and $13.1 \%$ of the participants had mild, moderate, severe, and extremely severe anxiety symptoms respectively, whereas only $7.8 \%$ and $2.6 \%$ had mild and moderate stress symptoms. (Table 3 )
Table 3. Magnitude and Severity of Homestay Followed Depression, Anxiety and Stress among College students in Addis Ababa, Ethiopia, May 2020.

\begin{tabular}{llll}
\hline \multirow{2}{*}{ Scale } & Depression & Anxiety & Stress \\
\cline { 2 - 4 } & $\mathbf{N}(\%)$ & $\mathbf{N}(\%)$ & $\mathbf{N}(\%)$ \\
\hline Normal & $75(49.0)$ & $74(48.4)$ & $136(88.9)$ \\
Mild & $28(18.3)$ & $17(11.1)$ & $12(7.8)$ \\
Moderate & $32(20.9)$ & $32(20.9)$ & $4(2.6)$ \\
Severe & $11(7.2)$ & $10(6.5)$ & $1(0.7)$ \\
Extremely severe & $7(4.6)$ & $20(13.1)$ & - \\
\hline
\end{tabular}




\subsubsection{The Overall Prevalence of Depression, Anxiety and} Stress

The overall prevalence of homestay followed depression, Anxiety, and Stress was observed at 51\% (95\%CI: $42.8-$ $59.1 \%), 51.6 \%(95 \% \mathrm{CI}: 43.4-59.8 \%)$, and $11.1 \%(95 \% \mathrm{CI}$ : 6.6-17.2\%) respectively (Figure 1).

\subsubsection{Predictors of Anxiety among College Students}

Monthly family income was statistically associated with anxiety symptoms during the pandemics of Covid-19. The odds of developing anxiety among the students with a family income of 2001-4999 birr and greater than 10,000 birr had 69.7\% (AOR: 0.303; 95\%CI: 0.102-0.901) and 79.5\% (AOR: 0.205 , 95\%CI: $0.064-0.653)$ higher odds as those with a monthly income of less than 2000 birr. (Table 4)

Table 4. Selected Socio-Demographic characteristics associated with Anxiety during Covid-19 pandemic among College Students in Addis Ababa, Ethiopia, May $2020(n=153)$.

\begin{tabular}{|c|c|c|c|c|c|}
\hline \multirow{2}{*}{ Characteristics } & \multirow{2}{*}{ Category } & \multicolumn{2}{|c|}{ Anxiety } & \multirow{2}{*}{$\operatorname{COR}(95 \% \mathrm{CI})$} & \multirow{2}{*}{ AOR $(95 \% C I)$} \\
\hline & & Yes & No & & \\
\hline \multirow[t]{2}{*}{ Gender } & Female & 53 & 53 & & \\
\hline & Male & 26 & 21 & $0.808(0.405-1.610$ & $1.120(0.490-2.558$ \\
\hline \multirow[t]{3}{*}{ Department } & $\mathrm{HO}$ & 30 & 20 & & \\
\hline & Nursing & 34 & 36 & $0.556(0.228-1.351)$ & $1.560(0.649-3.749)$ \\
\hline & Clinical Pharmacy & 15 & 18 & $0.882(0.385-2.024)$ & $2.229(0.825-6.026)$ \\
\hline \multirow[t]{5}{*}{ Academic Year } & $1^{\text {st }}$ & 3 & 3 & & \\
\hline & $2^{\text {nd }}$ & 19 & 23 & $1.333(0.173-10.254)$ & $1.605(0.101-25.481)$ \\
\hline & $3^{\text {rd }}$ & 28 & 21 & $1.333(0.244-7.279)$ & $1.543(0.165-14.474)$ \\
\hline & $4^{\text {th }}$ & 27 & 25 & $1.235(0.563-2.706)$ & $2.041(0.223-18.660)$ \\
\hline & $5^{\text {th }}$ & 2 & 2 & $1.00(0.704-3.702)$ & $0.832(0.091-7.574)$ \\
\hline \multirow[t]{3}{*}{ Age in years } & $\leq 21$ & 30 & 28 & & \\
\hline & $22-24$ & 36 & 35 & $1.042(0.520-2.085)$ & $0.834(0.370-1.882)$ \\
\hline & $\geq 25$ & 13 & 11 & $0.907(0.349-2.353)$ & $0.772(0.175-3.410)$ \\
\hline \multirow{4}{*}{$\begin{array}{l}\text { Family Monthly Income } \\
\text { In Birr }\end{array}$} & $\leq 2000$ & 10 & 21 & & \\
\hline & 2001-4999 & 23 & 17 & $0.352(0.132-0.938)^{*}$ & $0.303(0.102-0.901)^{*}$ \\
\hline & $5000-9999$ & 19 & 19 & $0.476(0.178-1.276)$ & $0.334(0.107-1.043)$ \\
\hline & $\geq 10000$ & 27 & 17 & $0.300(0.114-0.789)^{*}$ & $0.205(0.064-0.653)^{*}$ \\
\hline \multirow[t]{3}{*}{ With whom you live } & Alone & 4 & 2 & & \\
\hline & With parents & 61 & 64 & $2.098(0.371-11.874)$ & $3.615(0.446-29.327)$ \\
\hline & With Relatives & 14 & 8 & $1.143(0.170-7.693)$ & $1.396(0.149-12.887)$ \\
\hline
\end{tabular}

$* \mathrm{P}<0.05 ; * * \mathrm{P}<0.001$ statistically significant.

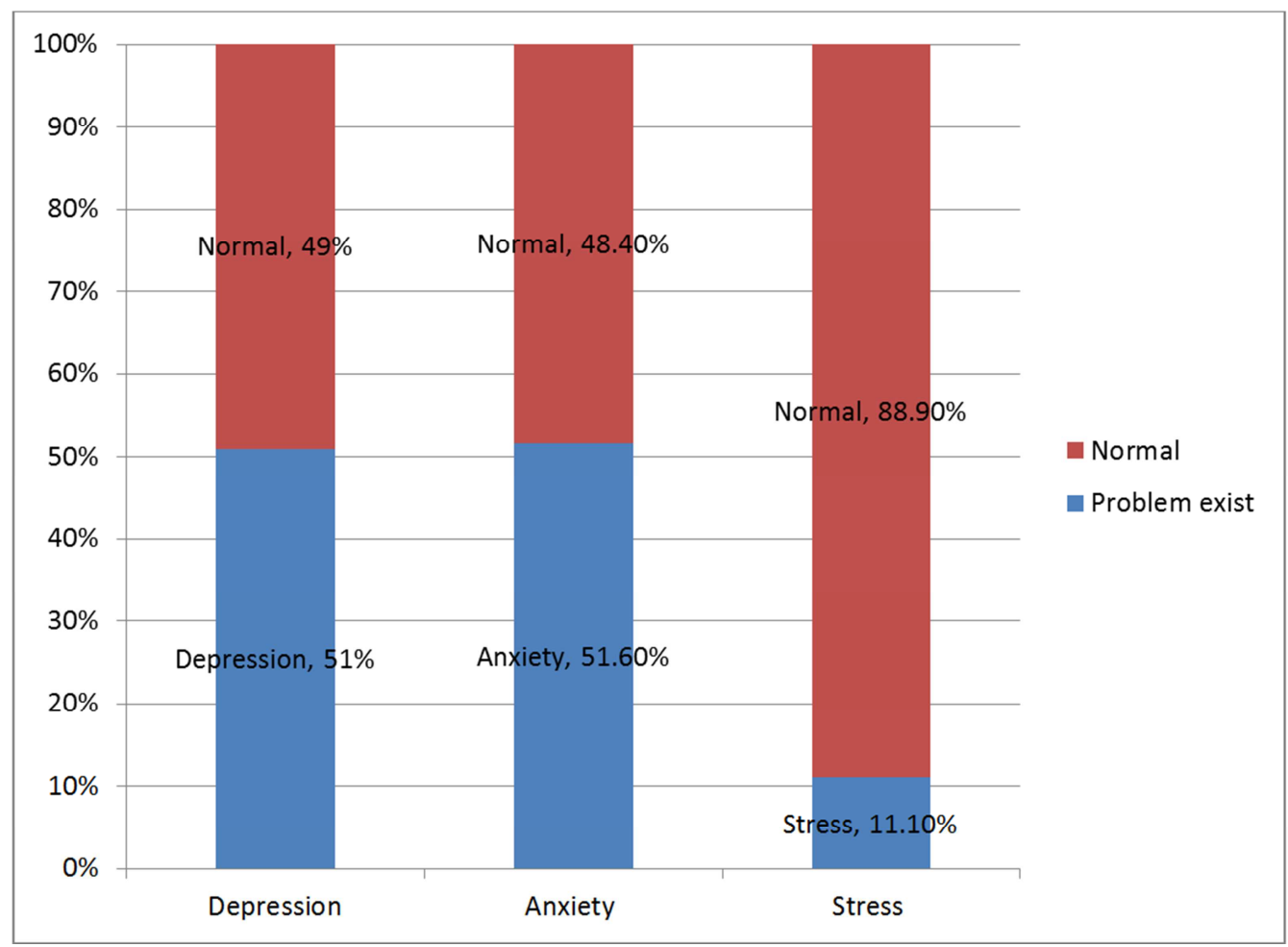

Figure 1. Overall Homestay Followed Prevalence of Depression, Anxiety and Stress among College Students in Addis Ababa, Ethiopia, May 2020. (n=153). 


\section{Discussion}

The overall prevalence of depression in this study was 51\%, which was consistent with the findings in Addis Ababa, where the prevalence of depression among medical students was $51.3 \%$ [13], 58.2\% in Nigeria [14], 51.3\% in Bhubaneswar, Odisha, India [15], and 52.3\% in Vietnam. [16]

The level of depression in this study was higher than other findings 26.8\% in Jimma Southwestern Ethiopia [17], 34.1\% in Mizan Aman College, Southern Ethiopia [18], 19.7\% in Debre Berhan, Central Ethiopia [19], 26.9\% in Kerala, India [20], $30 \%-36.4 \%$ in Malaysia [21, 22], and 43.7\% in Kenya. [23]

The prevalence of depression in this study was lower than the other finding at Fayoum University, Egypt, where the prevalence of depression was $60.8 \%$. [24]

The prevalence of anxiety in this study was $51.6 \%$ of which $11 \%, 20.9 \%, 6.5 \%$, and $13.1 \%$ of the participants had mild, moderate, severe and extremely severe anxiety symptoms respectively, and that was lower than the $66.9 \%$ prevalence in Bhubaneswar, Odisha, India [15], but higher than findings 23.6\% in Debre Berhan, Central Ethiopia [19], $30.1 \%$ in Addis Ababa [13], 12.9\% in Kenya [23] and 64.3\% in Egypt [24].

In this study, $11.1 \%$ of the respondents had stress symptoms with only $7.8 \%$ and $2.6 \%$ of which had mild and moderate stress symptoms. This was higher than $4.1 \%$ prevalence in Debre Berhan, Central Ethiopia [19]. The prevalence of anxiety in this study was lower than the findings at $53 \%$ in Bhubaneswar, Odisha, India [15], and $62.4 \%$ in Egypt. [24]

A study in the southern region of Ethiopia on severity of depression revealed that $26.83 \%, 6.71 \%$, and $0.61 \%$ of the respondents had mild, moderate and severe depression respectively [18] whereas, in this study, 49\%, 18.1\%, 20.9\%, $7.2 \%$ and $4.6 \%$ of participants had normal, mild, moderate, severe and extremely severe depression consecutively.

In this study, only family monthly income was associated with anxiety level. Students from a higher family monthly income were at an increased risk of developing anxiety. But which were missed in this study, the variables such as being a female (AOR 2.56, 95\% CI: 1.32, 4.95), first-year educational level (AOR 12.06, 95\% CI: 2.18, 66.72), secondyear educational level (AOR 8.99, 95\% CI: 1.67, 48.45) and those who had poor social support (AOR 5.36, 95\% CI: 2.08, 13.76) were significantly associated with anxiety. [13]

\section{Conclusion}

A higher prevalence of homestay followed depression, and anxiety was observed in the current study. The study also observed that there was a relatively high prevalence of stress level experienced by the college students in the study setting.

Regarding the predictor of anxiety during the pandemic of Covid-19; students with higher monthly family income sustained more level of anxiety compared to those with a lower family monthly income, which might be attributed to impact of containment following the pandemic. Mental Health status of College students during Covid-19 pandemic should be given an attention from multiple stakeholders in Addis Ababa.

\section{Limitations of the Study}

As this was an online survey, the sample size was low with a higher non-response rate. Common variables were not incorporated within the study, which results in the deficiency of undertaking factor identification. Associated factors for the stress and depression were not investigated due to sample size issues and the online nature of the study.

\section{Abbreviations}

AOR: Adjusted Odds Ratio

COR: Crude Odds Ratio

DAS: Depression, Anxiety, Stress

RNA: Ribonucleic Acid

WHO: World Health Organization

\section{Author's Contribution}

Addisu Tadesse Sahile involved in designing of the study, data analysis, drafting and critically reviewing the manuscript Mikiyas Ababu designed the online template, involved in data analysis, and review of the manuscript. Sinetsehay Alemayehu, Haymanot Abebe, Getabalew Endazenew, Mussie Wubshet, Hana Getachew and Tirhas Tadesse took part in designing of the study, and reviewing the final draft. All authors read and approved the final manuscript.

\section{Competing Interests}

The authors declare that they have no competing interests.

\section{Availability of Data and Materials}

A finding of this study was generated from data collected and analyzed on the basis of stated methods and materials hence all data were already available in the manuscript.

\section{Consent for Publication}

Consent for publication of the manuscript was not applicable due to the fact that there were no participant's individual data videos or images.

\section{Ethics Approval and Consent to Participate}

The study protocol was performed in accordance with the ethical principle. Ethical approval was obtained from ethics review board of Universal Medical and Business College. 
The ethics approval was given in accordance with the Declaration of Helsinki.

\section{Paper Context}

A mental health problem in college students is a public health issue this day. However, it is not investigated during the pandemic of COVID-19. Good Epidemiological data are essential to develop evidence based decision making pertaining the particular group.

This paper assessed the prevalence and severity of depression, anxiety and stress during the pandemic of COVID-19 among College students in Addis Ababa while contained at home off academic activities.

\section{Data Sharing Statement}

A finding of this study was generated from the data collected and analyzed on the basis of stated methods and materials hence all data were already available in the manuscript.

\section{Funding}

This study was funded by authors.

\section{Acknowledgements}

The authors would like to thank study participants for their willingness in taking part in the study.

\section{References}

[1] Tyrrell D, Bynoe M. Cultivation of viruses from a high proportion of patients with colds. Lancet. 1966: 76-7.

[2] Aggarwal V. EFFECTIVE WAYS TO MAKE CORONA VIRUS LOCKDOWN: PRODUCTIVE AND POSITIVE. Purakala with ISSN 0971-2143 is an UGC CARE Journal. 2020; 31 (4): 1798-807.

[3] Fisher BL, Fauci A. Meet the New Billionaires Club: COVID19 Vaccine Developers COVID-19 Meltdown and Pharma's Big Money Win.

[4] Mahase E. Coronavirus: covid-19 has killed more people than SARS and MERS combined, despite lower case fatality rate. British Medical Journal Publishing Group; 2020.

[5] Xiao C. A novel approach of consultation on 2019 novel coronavirus (COVID-19)-related psychological and mental problems: structured letter therapy. Psychiatry investigation. 2020; 17 (2): 175.

[6] Duan L, Zhu G. Psychological interventions for people affected by the COVID-19 epidemic. The Lancet Psychiatry. 2020; 7 (4): 300-2.

[7] Chen Q, Liang M, Li Y, Guo J, Fei D, Wang L, et al. Mental health care for medical staff in China during the COVID-19 outbreak. The Lancet Psychiatry. 2020; 7 (4): e15-e6.
[8] Li S, Wang Y, Yang Y, Lei X, Yang Y. Analysis of influencing factors of anxiety and emotional disorders in children and adolescents during home isolation during the epidemic of novel coronavirus pneumonia. Chinese Journal of Child Health. 2020: 1-9.

[9] Yang Y, Li W, Zhang Q, Zhang L, Cheung T, Xiang Y-T. Mental health services for older adults in China during the COVID-19 outbreak. The Lancet Psychiatry. 2020; 7 (4): e19.

[10] Organization WH. Coronavirus disease 2019 ( COVID-19): situation report, 92. 2020.

[11] Lobie TA, Tesfaye D, Abrham A. A narrative synthesis on COVID-19 risks and concerns in developing countries: The case of Ethiopia.

[12] Liu WJ, Musa R, Chew TF, Lim CTS, Morad Z, bin Bujang MA. DASS21: A useful tool in the psychological profile evaluation of dialysis patients. The American journal of the medical sciences. 2018; 355 (4): 322-30.

[13] Kebede MA, Anbessie B, Ayano G. Prevalence and predictors of depression and anxiety among medical students in Addis Ababa, Ethiopia. International journal of mental health systems. 2019; 13 (1): 30.

[14] Dabana A, Gobir AA. Depression among students of a Nigerian University: Prevalence and academic correlates. Archives of Medicine and Surgery. 2018; 3 (1): 6.

[15] Iqbal S, Gupta S, Venkatarao E. Stress, anxiety \& depression among medical undergraduate students \& their sociodemographic correlates. The Indian journal of medical research. 2015; 141 (3): 354.

[16] Tuyen NTH, Dat TQ, Nhung HTH. Prevalence of depressive symptoms and its related factors among students at Tra Vinh University, Vietnam in 2018. AIMS public health. 2019; 6 (3): 307.

[17] Teshome Hambisa M, Derese A, Abdeta T. Depressive symptoms among Haramaya University students in Ethiopia: a cross-sectional study. Depression research and treatment. 2020.

[18] Gebre BB, Mekonnen Z, Bedaso A. Magnitude of Depression and Associated Factors among Mizan Aman Health Science Student Southern Ethiopia. 2019.

[19] Abebe AM, Kebede YG, Mengistu F. Prevalence of Stress and Associated Factors among Regular Students at Debre Birhan Governmental and Nongovernmental Health Science Colleges North Showa Zone, Amhara Region, Ethiopia 2016. Psychiatry journal. 2018.

[20] Raghunathan D, Ramakrishnan D, Valsan KI, Ambika S. Prevalence of depression among students of a dental tertiary care center in Kerala. Indian journal of community medicine: official publication of Indian Association of Preventive \& Social Medicine. 2019; 44 (Suppl 1): S14.

[21] Islam MA, Low WY, Tong WT, Yuen CW, Abdullah A. Factors associated with depression among University Students in Malaysia: A cross-sectional study. KnE Life Sciences. 2018: 415-27-27.

[22] Nahas ARMF, Elkalmi RM, Al-Shami AM, Elsayed TM. Prevalence of depression among health sciences students: Findings from a public university in Malaysia. Journal of pharmacy \& bioallied sciences. 2019; 11 (2): 170. 
[23] Ndetei DM, Khasakhala L, Nyabola L, Ongecha-Owuor F, Seedat S, Mutiso V, et al. The prevalence of anxiety and depression symptoms and syndromes in Kenyan children and adolescents. Journal of Child \& Adolescent Mental Health. 2008; 20 (1): 33-51.
[24] Wahed WYA, Hassan SK. Prevalence and associated factors of stress, anxiety and depression among medical Fayoum University students. Alexandria Journal of medicine. 2017; 53 (1): 77-84. 